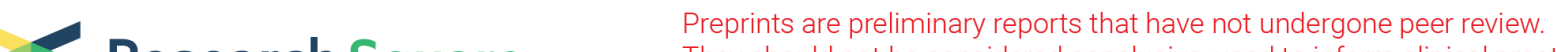 Research Square
They should not be onsidideded conllusive, used to inform clinical practice,
or referenced by the media salidated information.
}

\section{Accuracy of a Bedside Swallow Test After Extubation in ICU: A Prospective Validation of a Clinical Test Compared to a Fiberoptic Endoscopy.}

\section{Adel Maamar ( $\nabla$ adel.maamar@chu-rennes.fr)}

Centre Hospitalier Universitaire de Rennes https://orcid.org/0000-0001-8352-3613

\section{Valentine Parent}

Centre Hospitalier Universitaire de Rennes

\section{Emmanuel Guérot}

Hopital Europeen Georges Pompidou

\section{Pauline Berneau}

Centre Hospitalier Universitaire de Rennes

\section{Aurélien Frérou}

Centre Hospitalier Universitaire de Rennes

\section{Yves Le Tulzo}

Centre Hospitalier Universitaire de Rennes

\section{Bruno Laviolle}

Centre Hospitalier Universitaire de Rennes

\section{Franck Jégoux}

Centre Hospitalier Universitaire de Rennes

\section{Arnaud Gacouin}

Centre Hospitalier Universitaire de Rennes

\section{Jean-Marc Tadié}

Centre Hospitalier Universitaire de Rennes

\section{Research}

Keywords: Swallowing disorders, fiberoptic endoscopy, extubation, aspiration, pneumonia, endotracheal intubation

Posted Date: September 10th, 2020

DOI: https://doi.org/10.21203/rs.3.rs-58683/v1

License: (c) (1) This work is licensed under a Creative Commons Attribution 4.0 International License. Read Full License 


\section{Abstract}

Background: Swallowing disorders (SDs) are frequent after extubation in intensive care unit (ICU) exposing patients to aspiration pneumonia. There is no validated bedside swallowing evaluation (BSE) after extubation. We aimed to evaluate the accuracy of our BSE in comparison with fiberoptic endoscopic evaluation of swallowing (FEES) in critically ill patients after extubation, and to identify the incidence and risk factors of SD.

Methods: After a preliminary study in a first center, we conducted a 1-year prospective study as a validation cohort in a second center. Patients intubated for longer than 48 hours were included. Exclusion criteria were a known laryngeal pathology, a preexisting SD and an admission for stroke. FEES of the larynx and BSE were assessed within 24 hours after extubation to compare the accuracy of the BSE to the FEES procedure.

Results: One hundred and twenty eight patients were included, respectively 69 and 79 in the preliminary study and the validation cohort. Thirteen of $69(19 \%)$ and 33/79 (42\%) had SD assessed by FEES. The area under curve (AUC) reached respectively $0.86(95 \% \mathrm{Cl} 0.73-0.98)$ and $0.83(95 \% \mathrm{Cl} 0.74-0.92)$. Sensitivities were $77 \%$ (95\% Cl 0.54-0.99) and 85\% (95\% Cl 0.73-0.94), specificities $94 \%$ (95\% Cl 0.870.98 ) and $80 \%$ ( $95 \% \mathrm{Cl} 0.7-0.91$ ), and negative predictive values (NPV) were $95 \%$ and $90 \%$ in respectively preliminary study and validation cohort. Independent risk factors for SD were duration of intubation $(\mathrm{OR}=1.08 ; 95 \% \mathrm{Cl} 1.02-1.17, \mathrm{p}=0.03)$ and hemodynamic failure $(\mathrm{OR}=4.46 ; 95 \% \mathrm{Cl} 1.27-21, \mathrm{p}=0.03)$.

Conclusion: Our BSE is accurate to detect SDs after extubation in critically ill patients and can easily be implemented in an ICU setting.

\section{Introduction}

Swallowing dysfunction (SD) is a major issue in post-extubated patients as it can lead to aspiration, acute respiratory failure, health-care associated pneumonia, reintubation, and, consequently, prolonged intensive care unit (ICU) and hospital length of stay[1-3].

Several risks factors are known to increase the risk for SD including preexisting dysphagia (cancer, surgery and irradiation of the neck), stroke and neuromuscular diseases or critical illness polyneuromyopathy[4,5]. Patients known to have pre-existing swallowing dysfunction will be cautiously re-fed after extubation because they are at risk of aspiration[6,7]. Nonetheless, a large proportion of patients without any pre-existing swallowing disorders may be at risk for aspiration after extubation in the ICU since prolonged or multiple tracheal intubation could induce laryngeal injuries and SD which can be responsible for extubation failure[8]. Endoscopic studies have found that swallowing disorders and aspiration in critically ill patients are frequent and have been estimated to be present in 20 to 83\%[9-13] of patients intubated for longer than 48 hours. 
However, as emphasized in two recent reviews, there is no simple and reproducible bedside assessment of swallowing function after extubation in the ICU setting. Furthermore, endoscopic studies have demonstrated that expected clinical signs of aspiration such as cough, wheeze, stridor, tachypnea, cyanosis with feeds, oxygen desaturations, and noisy or wet breathing were not present in extubated patients with swallowing disorders and should be considered silent aspirators[14]. Currently, the most common diagnostic test to evaluate SD is performed by a speech language pathologist although $[15,16]$. There is no validated and accurate clinical assessment in this specific setting[17]. Consequently, fiberoptic endoscopic evaluation of swallowing (FEES) is considered the gold standard test to assess SD for recently extubated survivors of critical illness[16,18]. [14].

Since there is no validated clinical assessment of swallowing function, patients at risk should be evaluated using FEES. However, otorhinolaryngologists availability is the most important barrier for the routine use of FEES[19], and delay in evaluating swallowing function could be responsible for denutrition, electrolyte disturbance, necessity for feeding tube placement and increasing caregiver burden. Therefore, the development of effective screening strategies using bedside and reproducible assessments is crucial.

Herein, we developed a new clinical bedside swallowing evaluation (BSE) after extubation of critically ill patients. We aimed to prospectively evaluate the accuracy of our BSE in comparison with FEES as a gold standard in critically ill patients at risk to develop swallowing disorders following endotracheal intubation. A secondary aim was to identify the incidence of SD in this high-risk patient population and determine the risk factors for the development of SD.

\section{Methods}

\section{Study design}

A preliminary study was carried out using a fiberoptic endoscopic evaluation of post-intubation laryngeal injuries[8] in a 20-bed medical ICU (Hopital Européen Georges Pompidou, Paris).

Then, we performed a prospective study over a 1-year period in our Intensive Care Unit admitting mostly medical patients at the Rennes University Hospital, a tertiary teaching hospital. This study was approved by the hospital's ethical committee (no. 16.143). As FEES is considered routine care in our ICU to assess SD for recently extubated survivors of critical illness, patient informed consent was waived by the ethical committee.

\section{Patient eligibility}

Criteria for inclusion were as follows: intubation for more than $48 \mathrm{~h}$; extubation after a successful weaning trial of $1 \mathrm{~h}$ through a T-piece[8]; ability to maintain a sitting position; Glasgow coma scale after extubation of 15 .

Exclusion criteria were a known laryngeal pathology, a preexisting swallowing disorder and an admission for stroke. We also excluded all patients for whom we were unable to perform the BSE or FEES within the 
first 24 hours following extubation and all patients who refused FEES.

All patients were orally intubated with soft, high-volume, low-pressure cuffed endotracheal tube (ETT) (Mallinckrodt Medical, Athlone, Ireland). All intubations were performed by experienced intensivists. During the ICU stay, cuff pressures were checked every $4 \mathrm{~h}$ to maintain a pressure $<25 \mathrm{cmH}_{2} \mathrm{O}$.

\section{Extubation procedure}

Extubation was decided by the patient's attending physician after a successful $1 \mathrm{~h}$ spontaneous breathing trial. Planned extubations were performed by respiratory therapists as previously reported[8].

\section{Bedside evaluation}

According to the preliminary study, the BSE comprised a clinical evaluation of eight items as shown in Table 1. The items included in the BSE were chosen to explore the first phases of normal swallowing[18], according to the previous identified risk factors, and a retrospective analysis of factors present in patients whom had a SD[8]. Thus, the oral praxis skills, salivary stasis and mobility of the tongue explore the oral phase; tone of the flexor muscles of the neck and ability to maintain head lifted explore the pharyngeal phase; voluntary coughing and clear voice explore the signs of aspiration; and the post-extubation stridor explore the presence of laryngeal injuries[8]. Post-extubation stridor was defined as an audible inspiratory wheeze after extubation. Each item was counted as one point. Therefore, the possible scores for the BSE ranged from 0 to 8 .

A bedside evaluation was conducted within $24 \mathrm{~h}$ after extubation by two physiotherapists and before the FEES procedure. The BSE was performed without knowledge of the FEES results. Reproducibility of the BSE between the two physiotherapists, several nurses and physicians was tested on the 30 first patients.

\section{Endoscopic evaluation}

A laryngeal nasofibroscopy was performed within $24 \mathrm{~h}$ after extubation by two experienced otolaryngologists. The FEES procedure was performed in bed or on a chair for all patients with the back elevated to at least $75^{\circ}$. A fiberoptic laryngoscope (Karl Storz Endoskope ${ }^{\mathrm{TM}} 11101 \mathrm{SP}$, Tuttlingen, Germany, $30 \mathrm{~cm}$ long and of $3.5 \mathrm{~mm}$ diameter was used with a Karl Storz ${ }^{\mathrm{TM}} 11301$ DF cold light supply for illumination) was passed transnasally to the nasopharynx, oropharynx, and supraglottic area to allow adequate visualization of the structures involved in swallowing. No topical anesthetic or other preparation was used before placing the scope in the nose. Gastric tube, if it was present, was not removed during the procedure. Stained liquid and semi-liquid boluses were then given. Otolaryngologists assessed the ability to protect the airway and to uphold airway protection, the capability to clear the bolus during deglutition, the presence of pooling and residual material in the hypopharynx. We defined swallowing disorder (positive FEES) as a Penetration Aspiration Scale (PAS)[20] > 1 (Supplementary Table 1). The FEES was performed after BSE, without knowledge of the BSE result[14].

\section{Data collection}


We prospectively collected the following parameters: age, sex, body mass index (BMI), severity of illness at admission according to the simplified acute physiological score[21] (SAPS II) and the sequential organ failure assessment score[22] (SOFA) at admission, main indication for intubation (neurologic failure, acute respiratory failure, hemodynamic failure and surgery), intubation characteristics (emergency or planned for surgery), use of sedation or myorelaxant drugs for intubation, the duration of intubation, ETT diameter (expressed in millimeters) and patient's height/ETT diameter ratio[8], history of self-extubation, and the number of intubations during ICU stay before inclusion. We also recorded if patients had a shock (a need for dobutamine, epinephrine, or norepinephrine treatment during intubation period), if they received steroids prior to extubation (at least $50 \mathrm{mg}$ equivalent of methylprednisolone per day during the period of intubation) and their SOFA score at the day of extubation[22]. After extubation, the patients were monitored for 28 days and the following parameters were recorded: extubation failure (defined as the need to reintubate the patient in the first week following extubation, regardless of cause), the development of pneumonia within 28 days after extubation[23], ICU length of stay, and vital status within 28 days after extubation.

\section{Endpoints}

The primary endpoint was the accuracy of the BSE compared to the FEES procedure. Secondary endpoints were the incidence of SD, pneumonia and death occurrence within the 28 first days, and to identify risk factors for SDs.

\section{Statistical analysis}

Based on the literature and our preliminary study, we hypothesized a prevalence of 0.30 and an expected sensitivity of 0.80 with a minimal lower confidence interval of 0.6 ; these estimates allowed us to calculate a sample size of 76 patients[24].

Normally distributed continuous variables are presented as the means \pm standard deviations (SDs), whereas non-normally distributed data are presented as medians [Interquartile ranges (IQRs)]. Categorical variables are presented as numbers (percentages). We identified risk factors for swallowing disorder using univariate and multivariate analysis. The two groups (normal swallowing vs. swallowing disorder) were compared using the Mann-Whitney test for continuous variables and $a \chi^{2}$ or Fisher's exact test when more appropriate for categorical variables. A descendant stepwise logistic regression analysis was performed to determine the independent factors of swallowing disorders with $p=0.20$ for enter. Among related factors (SAPS II at admission and SOFA at intubation) only the most clinically relevant (SAPS II for severity) were included in the multivariate analysis model to minimize the effect of collinearity. Thus, the variables entered into the multivariate analysis were SAPS II at admission, hemodynamic failure, intubation characteristics (emergency or planned for surgery), duration of intubation and main indication for intubation. The findings of the FEES were considered the gold standard and were compared with the results of BSE. Ninety-five percent confidence intervals $(95 \% \mathrm{Cl})$ were calculated as exact binomial confidence intervals. The accuracy of the BSE was assessed by the mean of receiver operating 
characteristics (ROC) curves and the area under curve (AUC). The threshold value of the BSE was then determined from analysis of the ROC curves as the value that led to the best compromise between sensitivity and specificity. Statistical analyses were performed using R 3.6.2 (R Foundation for Statistical Computing, Vienna, Austria), and $p$ values of less than 0.05 were considered significant.

\section{Results}

\section{Preliminary study}

During the preliminary study, 69 patients were included, 13 (19\%) had SD assessed by FEES. The area under curve (AUC) reached $0.86(95 \% \mathrm{Cl} 0.73-0.98)$. As shown in Figure 1, the value of BSE score of zero was determined from the ROC as the most accurate to detect a swallowing disorder, with a sensitivity of $77 \%$ (95\% Cl 0.54-0.99), a specificity of $94 \%$ (95\% Cl 0.87-0.98), a predictive positive value (PVV) of $75 \%$ and a negative predictive value (NPV) of $95 \%$.

\section{Main study}

\section{Participants}

During the one year study period, 212 patients were eligible for inclusion (Figure 2); 133 were excluded for the following reasons: 37 (17\%) patients were reintubated before both evaluations, 2 died before both evaluations, and 8 were transferred to a different hospital before extubation. Unavailability of a FEES operator affected $74(55.6 \%)$ patients. Finally, 12 patients refused FEES examination before or at the beginning of the procedure. Thus, 79 patients were included in the validation cohort. The time interval between BSE and FEES was $6.8 \pm 5.7 \mathrm{~h}$ (mean \pm SD) and there was no clinical intervention between the two tests. Of note, no FEES complications were observed.

\section{Test results}

FEES was positive for 33 patients (42\%), and BSE was positive for 29 of them. The accuracy of the BSE is shown in Figure 3. The AUC reached $0.83(95 \% \mathrm{Cl}$ 0.74-0.92). The BSE value of zero was determined from the ROC as the most accurate to detect a swallowing disorder, with a sensitivity of $85 \%(95 \% \mathrm{Cl} 0.73-0.94)$ and a specificity of $80 \%$ (95\% Cl $0.7-0.91)$, a PVV of $72 \%$ and a NPV of $90 \%$.

This study complied with the STARD guidelines on reporting accuracy studies and the reproducibility of BSE between the physiotherapists, several nurses and physicians was tested on the 30 first patients and reached $93 \%$.

\section{Risk factors for swallowing disorders}

Thirty-three patients (42\%) had swallowing disorders (using endoscopic criteria). The characteristics of patients with and without SD are shown in Table 2. Swallowing disorders were significantly associated with hemodynamic failure requiring vasopressor infusion, longer duration of mechanical ventilation and 
intubation for respiratory failure. Independent risk factors for SD were duration of intubation $(O R=1.08$; $95 \% \mathrm{Cl} 1.02-1.17, \mathrm{p}=0.03)$ and hemodynamic failure requiring vasopressor infusion $(\mathrm{OR}=4.46 ; 95 \% \mathrm{Cl}$ $1.27-21, p=0.03)$.

\section{8-Day follow-up}

Among the study population, 10 (12.7\%) patients developed pneumonia during the follow-up period. Five had SD assessed by FEES and 5 had no evidence of SD shown by FEES. Among these 10 patients, 4 died within the 28 first days.

Among the 33 patients who presented swallowing disorder, 5 (15\%) developed pneumonia and $3(10 \%)$ died within the first 28 days after extubation.

\section{Discussion}

We demonstrated that swallowing dysfunction is common after prolonged tracheal intubation and can easily be diagnosed using a simple and reliable bedside swallowing evaluation.

We found in our study that $42 \%$ of patients who were intubated for more than 48 hours presented swallowing dysfunction. With a BSE score of zero, the AUC reached $0.86(95 \% \mathrm{Cl} 0.73-0.98)$ in the preliminary study and $0.83(95 \% \mathrm{Cl} 0.74-0.92)$ in the validation cohort, with good sensitivities, specificities and NPV in both cohorts. Our findings are in accordance with other studies that used FEES evaluation. For instance, El Solh et al.[9] found that up to $50 \%$ of patients had swallowing disorders after extubation. Among the risk factors, duration of intubation and severity at admission defined as the need for vasopressors were associated with SD. Duration of endotracheal intubation has previously been associated with laryngeal injuries that can promote swallowing dysfunction along with loss of muscle strength attributable to non-use during intubation and loss of proprioception[15,25]. Furthermore, the association between a need for vasopressor (i.e., hemodynamic failure) and swallowing dysfunction might be explained by the effects of vasopressor therapy, which induces neuronal dysfunction that can diminish both the sensitivity and mobility of laryngeal and pharyngeal structures[26,27]. Since SD is frequent, the early identification of SD can reduce the occurrence of pulmonary complications after extubation. For instance, Barquist reported the onset of aspiration pneumonia after extubation in $15 \%$ of patients[11]. The high probability and potential severity of aspiration pneumonia emphasize the need for the early screening of extubated patients. Furthermore, swallowing evaluation should be performed early to limit nutrition deprivation.

Fiberoptic evaluation of swallowing (FEES) is considered the gold standard test for the assessment of SD in recently extubated survivors of critical illness. This technique has several advantages: First, it can be performed at the bedside and does not require patient transportation outside the ICU. Second, it allows direct visualization of the larynx and of the movement of the pharyngeal and glottic structures, including the vocal cords and the proximal trachea. However, FEES has several limitations. Although it can be considered as invasive and uncomfortable by some patients, equipment and otorhinolaryngologist 
availability are the most important barriers to the routine use of FEES. For example, a national survey in the US showed that endoscopy is available in only $41 \%$ of hospitals caring for recently extubated patients; furthermore, even when available, FEES is used only $15 \%$ of the time in university hospitals and $8 \%$ of the time in general hospitals[19]. Our study emphasizes this issue, as 74 (55\% of the excluded patients) patients were excluded because of unavailability of FEES operator. Consequently, a simple clinical bedside swallowing evaluation could be of benefit for intubated patients in the ICU. First, this evaluation is easy to implement, cost-effective and non-invasive, which could make it available in all ICUs. Second, a systematic and accurate method of detecting swallowing disorders might decrease aspiration pneumonia by allowing modifications of the care of these patients, such as implementing enteral feeding tube placement and providing rapid care by speech-language practitioners. Finally, it could allow rapid oral feeding in patients whose swallowing evaluation has been found normal. Indeed, caloric deficit has been reported to be associated with increased nosocomial infection rates, especially bloodstream infections[28] and pneumonia, as well as higher mortality[29], longer ICU stays, and higher healthcare costs[30,31].

Our BSE is reproducible and accurate in detecting swallowing disorders. The high sensitivity (85\%) and specificity $(80 \%)$ of our clinical BSE can allow practitioners to resume oral feeding earlier in eligible patients and to decrease aspiration in patients who have SD. Furthermore, the good negative predictive value (90\%) of our test allows us to miss very few "aspirators" and avoid unnecessary instrumented examination. Other studies have previously proposed bedside swallowing assessments, mainly in stroke patients[31-33]. However, these assessments have been criticized for their poor standardization, accuracy, and inter-rater and intra-rater reliability scores. Our study has several limitations. First, although FEES is considered as the gold standard test to assess SD for recently extubated survivors of critical illness, we cannot rule out missed diagnoses of SD. However, several studies have shown a better interobserver variability and sensitivity for the detection of aspiration[34-36] for FEES than for a modified barium swallow. Second, 133 patients were excluded mainly due to a lack of availability of otorhinolaryngologists to perform FEES. This fact emphasizes that FEES availability is the most important barrier to its routine use[19] ; unfortunately, however, we cannot exclude selection bias. Finally, we did not assess the evolution of swallowing disorder using a second FEES, which could have been of interest. Few studies have focused on the duration of swallowing disorders in survivors of critical illness. El Solh et al.[9] showed that at day 5 and day 14 after extubation, $40 \%$ and $14 \%$ of elderly patients had endoscopically confirmed aspiration, respectively [25]. Another study showed an improvement in swallowing delay in all patients at 7 days after extubation; however, swallowing function was assessed by submental electromyogram. More recently, a retrospective cohort showed persistent swallowing disorders in $35 \%$ of SD patients at hospital discharge[37].

\section{Conclusion}

This study presents a simple and accurate bedside swallow evaluation providing a previously unreached level of sensitivity and specificity. We also found that swallowing disorders were independently associated with duration of intubation and hemodynamic failure requiring vasopressor infusion. These 
findings might allow ICU practitioners to decrease aspiration in patients with swallowing disorders. Additionally, the results might allow aspiration-related specific therapy and clinical outcomes to be improved.

\section{Declarations}

\section{Ethical approval and consent to participate}

The ethical committee (no. 16.143) of Rennes University Hospital approved this study. All patients were informed. As FEES is considered routine care in our ICU to assess SD for recently extubated survivors of critical illness, patient informed consent was waived by the ethical committee.

\section{Consent for publication}

Not applicable.

\section{Availability of data and materials}

All data generated or analyzed during this study are included in this article and its supplementary information files.

\section{Competing interests}

On behalf of all authors, the corresponding author states that there are no conflicts of interest.

\section{Funding}

None.

\section{Authors' contributions}

AM conceptualized the study and participated in its design, data acquisition and analysis, literature research, and manuscript drafting. VP participated in the literature research, data acquisition and analysis, and the drafting of the manuscript. AG participated in data acquisition and analysis, revising of the article for important intellectual content and manuscript drafting. PB participated in data acquisition and analysis and manuscript drafting. EG conceptualized the study, participated in data acquisition and analysis and manuscript drafting. AF participated in data acquisition and analysis and manuscript drafting. SR participated in data acquisition and analysis and manuscript drafting. ML participated in data acquisition and analysis and manuscript drafting. YLT participated in revising the article for important intellectual content and manuscript drafting. BL participated in data analysis and manuscript drafting. FJ participated in the literature research, data acquisition and analysis, and manuscript drafting. JMT conceptualized the study and participated in its design, data analysis, and manuscript drafting and revision for important intellectual content. All authors read and approved the final manuscript. 
Acknowledgments

The authors acknowledge the physiotherapists of the ICU department, Emmanuelle Prudhomme and Emilie Ravaudet for their participation.

\section{References}

1. Loeb M, McGeer A, McArthur M, Walter S, Simor AE. Risk factors for pneumonia and other lower respiratory tract infections in elderly residents of long-term care facilities. Arch Intern Med. 1999;159:2058-64.

2. Marik PE, Kaplan D. Aspiration pneumonia and dysphagia in the elderly. Chest. 2003;124:328-36.

3. Martin BJ, Corlew MM, Wood H, Olson D, Golopol LA, Wingo M, et al. The association of swallowing dysfunction and aspiration pneumonia. Dysphagia. 1994;9:1-6.

4. Katzan IL, Dawson NV, Thomas CL, Votruba ME, Cebul RD. The cost of pneumonia after acute stroke. Neurology. 2007;68:1938-43.

5. Smithard DG, O'Neill PA, Parks C, Morris J. Complications and outcome after acute stroke. Does dysphagia matter? Stroke. 1996;27:1200-4.

6. Goldsmith T. Evaluation and treatment of swallowing disorders following endotracheal intubation and tracheostomy. Int Anesthesiol Clin. 2000;38:219-42.

7. DeVita MA, Spierer-Rundback L. Swallowing disorders in patients with prolonged orotracheal intubation or tracheostomy tubes. Crit Care Med. 1990;18:1328-30.

8. Tadié J-M, Behm E, Lecuyer L, Benhmamed R, Hans S, Brasnu D, et al. Post-intubation laryngeal injuries and extubation failure: a fiberoptic endoscopic study. Intensive Care Med. 2010;36:991-8.

9. El Solh A, Okada M, Bhat A, Pietrantoni C. Swallowing disorders post orotracheal intubation in the elderly. Intensive Care Med. 2003;29:1451-5.

10. Barker J, Martino R, Reichardt B, Hickey EJ, Ralph-Edwards A. Incidence and impact of dysphagia in patients receiving prolonged endotracheal intubation after cardiac surgery. Can J Surg J Can Chir. 2009;52:119-24.

11. Barquist E, Brown M, Cohn S, Lundy D, Jackowski J. Postextubation fiberoptic endoscopic evaluation of swallowing after prolonged endotracheal intubation: a randomized, prospective trial. Crit Care Med. 2001;29:1710-3.

12. Tolep K, Getch CL, Criner GJ. Swallowing dysfunction in patients receiving prolonged mechanical ventilation. Chest. 1996;109:167-72.

13. Ajemian MS, Nirmul GB, Anderson MT, Zirlen DM, Kwasnik EM. Routine fiberoptic endoscopic evaluation of swallowing following prolonged intubation: implications for management. Arch Surg Chic III 1960. 2001;136:434-7.

14. Hafner G, Neuhuber A, Hirtenfelder S, Schmedler B, Eckel HE. Fiberoptic endoscopic evaluation of swallowing in intensive care unit patients. Eur Arch Oto-Rhino-Laryngol Off $\mathrm{J}$ Eur Fed Oto-Rhino- 
Laryngol Soc EUFOS Affil Ger Soc Oto-Rhino-Laryngol - Head Neck Surg. 2008;265:441-6.

15. Macht M, White SD, Moss M. Swallowing dysfunction after critical illness. Chest. 2014;146:1681-9.

16. Skoretz SA, Flowers HL, Martino R. The incidence of dysphagia following endotracheal intubation: a systematic review. Chest. 2010;137:665-73.

17. Brodsky MB, Suiter DM, González-Fernández M, Michtalik HJ, Frymark TB, Venediktov R, et al. Screening Accuracy for Aspiration Using Bedside Water Swallow Tests: A Systematic Review and Meta-Analysis. Chest. 2016;150:148-63.

18. Macht M, Wimbish T, Bodine C, Moss M. ICU-acquired swallowing disorders. Crit Care Med. 2013;41:2396-405.

19. Macht M, Wimbish T, Clark BJ, Benson AB, Burnham EL, Williams A, et al. Diagnosis and treatment of post-extubation dysphagia: results from a national survey. J Crit Care. 2012;27:578-86.

20. Rosenbek JC, Robbins JA, Roecker EB, Coyle JL, Wood JL. A penetration-aspiration scale. Dysphagia. 1996;11:93-8.

21. Le Gall JR, Lemeshow S, Saulnier F. A new Simplified Acute Physiology Score (SAPS II) based on a European/North American multicenter study. JAMA J Am Med Assoc. 1993;270:2957-63.

22. Vincent JL, de Mendonça A, Cantraine F, Moreno R, Takala J, Suter PM, et al. Use of the SOFA score to assess the incidence of organ dysfunction/failure in intensive care units: results of a multicenter, prospective study. Working group on "sepsis-related problems" of the European Society of Intensive Care Medicine. Crit Care Med. 1998;26:1793-800.

23. Chastre J, Fagon J-Y. Ventilator-associated pneumonia. Am J Respir Crit Care Med. 2002;165:867903.

24. Flahault A, Cadilhac M, Thomas G. Sample size calculation should be performed for design accuracy in diagnostic test studies. J Clin Epidemiol. 2005;58:859-62.

25. de Larminat V, Montravers P, Dureuil B, Desmonts JM. Alteration in swallowing reflex after extubation in intensive care unit patients. Crit Care Med. 1995;23:486-90.

26. Puthucheary Z, Harridge S, Hart N. Skeletal muscle dysfunction in critical care: wasting, weakness, and rehabilitation strategies. Crit Care Med. 2010;38:S676-682.

27. Tobin MJ. Narrative Review: Ventilator-Induced Respiratory Muscle Weakness. Ann Intern Med. 2010;153:240.

28. Ekpe K, Novara A, Mainardi J-L, Fagon J-Y, Faisy C. Methicillin-resistant Staphylococcus aureus bloodstream infections are associated with a higher energy deficit than other ICU-acquired bacteremia. Intensive Care Med. 2014;40:1878-87.

29. Faisy C, Lerolle N, Dachraoui F, Savard J-F, Abboud I, Tadie J-M, et al. Impact of energy deficit calculated by a predictive method on outcome in medical patients requiring prolonged acute mechanical ventilation. Br J Nutr. 2009;101:1079-87.

30. Berger MM, Pichard C. Best timing for energy provision during critical illness. Crit Care. 2012;16:215. 
31. Villet S, Chiolero RL, Bollmann MD, Revelly J-P, Cayeux R N M-C, Delarue J, et al. Negative impact of hypocaloric feeding and energy balance on clinical outcome in ICU patients. Clin Nutr Edinb Scotl. 2005;24:502-9.

32. McCullough GH, Wertz RT, Rosenbek JC. Sensitivity and specificity of clinical/bedside examination signs for detecting aspiration in adults subsequent to stroke. J Commun Disord. 2001;34:55-72.

33. McCullough GH, Wertz RT, Rosenbek JC, Mills RH, Ross KB, Ashford JR. Inter- and intrajudge reliability of a clinical examination of swallowing in adults. Dysphagia. 2000;15:58-67.

34. Colodny N. Interjudge and intrajudge reliabilities in fiberoptic endoscopic evaluation of swallowing (fees) using the penetration-aspiration scale: a replication study. Dysphagia. 2002;17:308-15.

35. Kelly AM, Drinnan MJ, Leslie P. Assessing penetration and aspiration: how do videofluoroscopy and fiberoptic endoscopic evaluation of swallowing compare? The Laryngoscope. 2007;117:1723-7.

36. Leder SB, Acton LM, Lisitano HL, Murray JT. Fiberoptic endoscopic evaluation of swallowing (FEES) with and without blue-dyed food. Dysphagia. 2005;20:157-62.

37. Macht M, Wimbish T, Clark BJ, Benson AB, Burnham EL, Williams A, et al. Postextubation dysphagia is persistent and associated with poor outcomes in survivors of critical illness. Crit Care Lond Engl. 2011;15:R231.

\section{Tables}

Table 1: Clinical bedside swallowing evaluation

\begin{tabular}{|ll|}
\hline Normal tone of the flexor muscles of the neck & 1 \\
\hline Clear voice & 1 \\
\hline Ability to maintain head lifted & 1 \\
\hline Mobility of the tongue & 1 \\
\hline Voluntary coughing & 1 \\
\hline Normal oral praxis skills & 1 \\
\hline Salivary stasis & 1 \\
\hline Post-extubation stridor & 1 \\
\hline
\end{tabular}

Table 2: Characteristics of patients with and without swallowing disorder. 


\begin{tabular}{|c|c|c|c|}
\hline Characteristics & $\begin{array}{l}\text { No swallowing disorder } \\
(n=46)\end{array}$ & Swallowing disorder $(n=33)$ & $\mathrm{p}$ value \\
\hline Male & $27(58.7)$ & $16(48.5)$ & 0.4 \\
\hline Age, years & $63[53.5-69]$ & $65[56-70]$ & 0.41 \\
\hline BMI & $24.5[22.2-30.5]$ & $26.9[23.4-30.3]$ & 0.5 \\
\hline Shock & $29(63)$ & $30(90.9)$ & 0.01 \\
\hline SAPS II & $49.5[36.3-59.8]$ & 57 [38-68] & 0.14 \\
\hline SOFA at intubation & 8 [6-11] & 9 [8-12] & 0.18 \\
\hline SOFA at extubation & $2[0-3.8]$ & $2[1-3]$ & 0.48 \\
\hline Intubation & & & 0.16 \\
\hline Emergency & $39(84.8)$ & $32(97)$ & \\
\hline Planned & $7(15.2)$ & $1(3)$ & \\
\hline Steroid therapy & $21(45.7)$ & $14(42.4)$ & 0.8 \\
\hline Duration of intubation, days & $6[3.3-10.8]$ & $11[7-20]$ & 0.001 \\
\hline History of self-extubation & $2(4.3)$ & $1(3)$ & 0.8 \\
\hline Number of intubations & $1[1-1]$ & $1[1-2]$ & 0.63 \\
\hline Height/ETT ratio & 230 [221.3-236.9] & 228.6 [217.9-235.5] & 0.85 \\
\hline Setting of intubation & & & 0.9 \\
\hline Pre-hospital & $3(6.5)$ & $3(9.1)$ & \\
\hline Hospital & $43(93.5)$ & $30(90.9)$ & \\
\hline \multicolumn{4}{|l|}{ Use during intubation } \\
\hline Myorelaxant drug & $46(100)$ & 31 (93.9) & 0.9 \\
\hline Sedation & $46(100)$ & 31 (93.9) & 0.9 \\
\hline Main indication for intubation & & & 0.04 \\
\hline
\end{tabular}




\begin{tabular}{|lll|} 
Surgery & $7(15.2)$ & $1(3)$ \\
\hline Neurologic failure & $20(43.5)$ & $9(27.3)$ \\
\hline Acute respiratory failure & $17(37)$ & $18(54.5)$ \\
\hline Hemodynamic failure & $2(4.3)$ & $5(15.2)$ \\
\hline
\end{tabular}

Definition of abbreviations: BMI = Body mass index, SAPS $=$ Simplified Acute Physiologic Score, SOFA = Sequential Organ Failure Assessment, ETT = Endotracheal Tube. Data are median [interquartile range] for continuous variables and number (\%) for categorical variables.

\section{Figures}

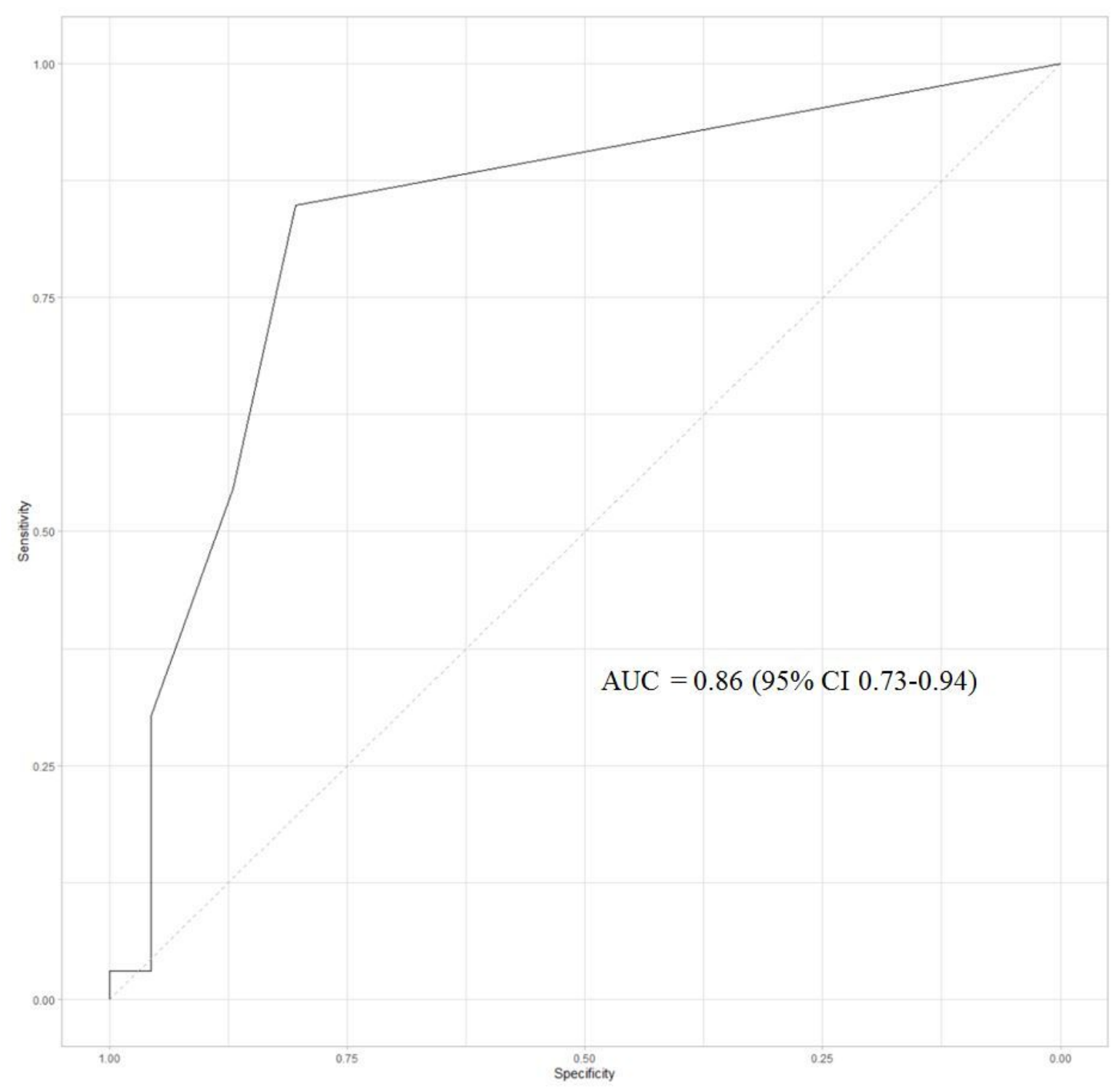

Figure 1 
Receiver-operating characteristics (ROC) plot of the preliminary study. True positive fraction is plotted on $y$-axis and the true-negative fraction is plotted on x-axis. The BSE threshold value of 0 was determined as the most accurate to detect a SD.

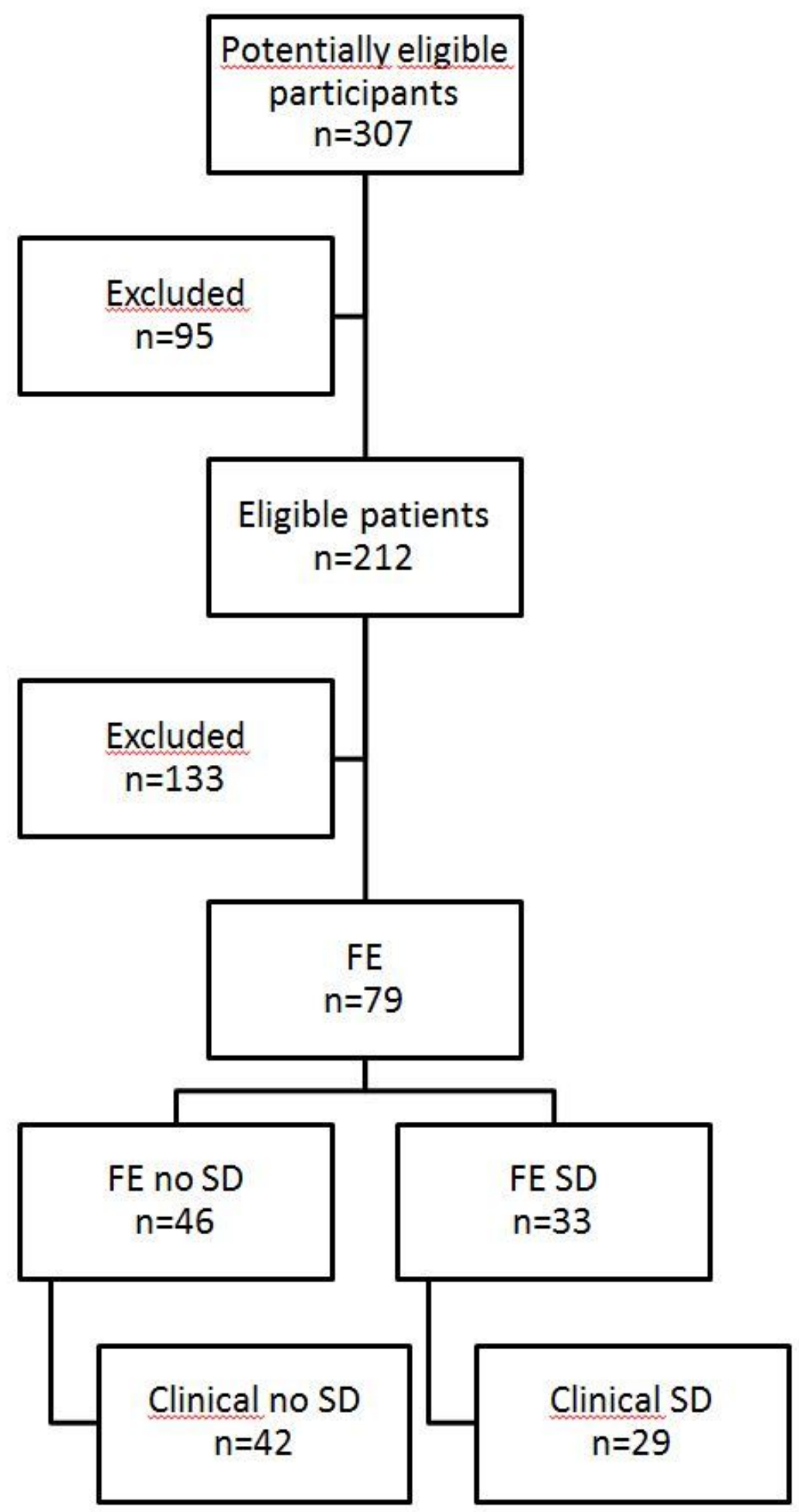

Figure 2

Diagram flowchart of patients. 


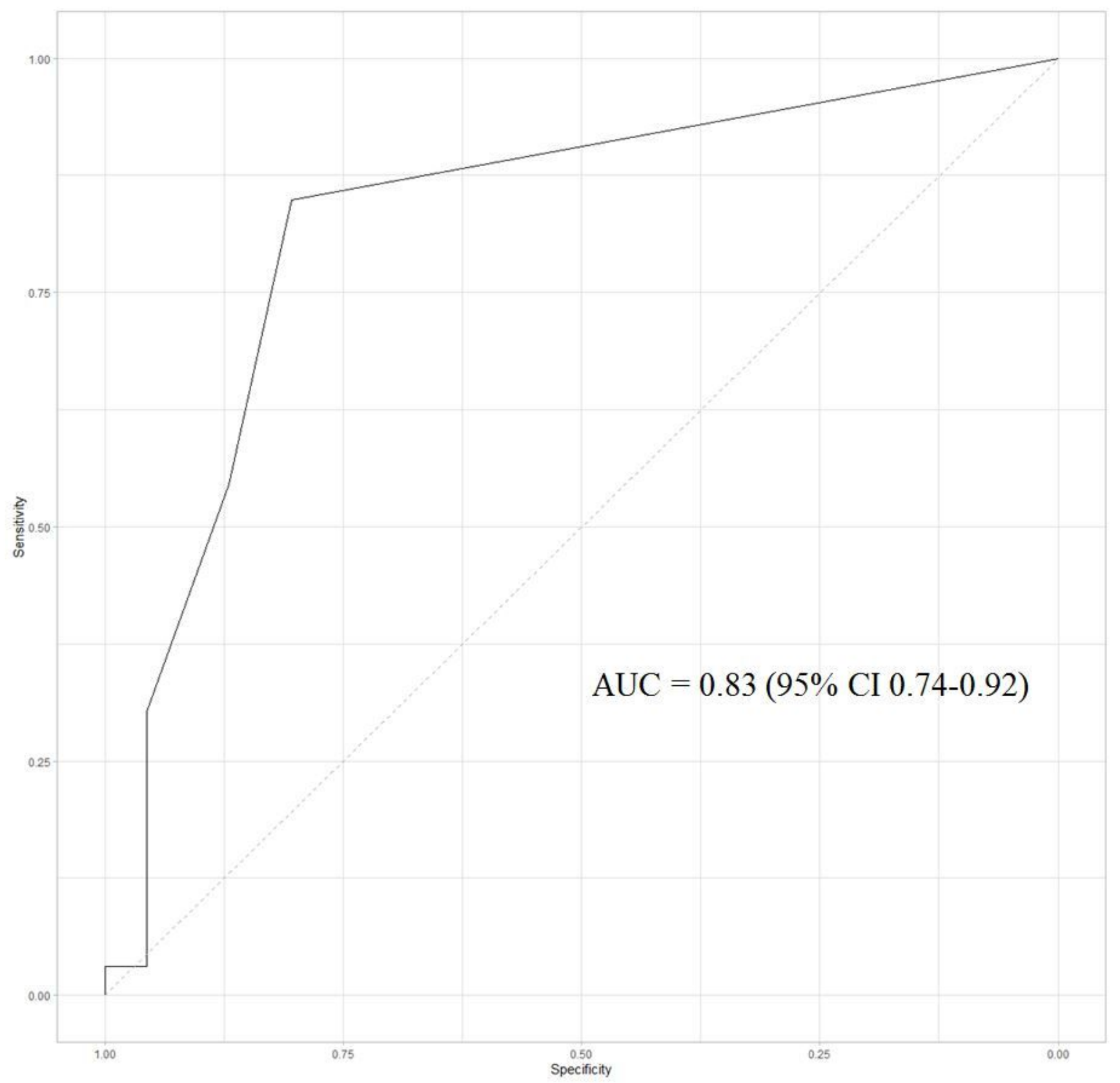

Figure 3

Receiver-operating characteristics (ROC) plot of the main study (validation cohort). True positive fraction is plotted on $y$-axis and the true-negative fraction is plotted on $x$-axis. The BSE threshold value of 0 was determined as the most accurate to detect a SD.

\section{Supplementary Files}

This is a list of supplementary files associated with this preprint. Click to download.

- SupplementaryTable1.docx 